\title{
Comparison between the Reflux Finding Score and the Reflux Symptom Index in the Practice of Otorhinolaryngology
}

\author{
Heloisa Sobreira Nunes ${ }^{1}$ José Antonio Pinto ${ }^{1}$ Adma Roberta Zavanela ${ }^{1}$ André Freitas Cavallini ${ }^{1}$ \\ Gabriel Santos Freitas ${ }^{1}$ Fabiola Esteves Garcia ${ }^{1}$ \\ ${ }^{1}$ Department of Otolaryngology, Núcleo de Otorrinolaringologia e \\ Cirurgia de Cabeça e Pescoço de São Paulo, São Paulo, Brazil \\ Int Arch Otorhinolaryngol 2016;20:218-221. \\ Address for correspondence Heloisa Sobreira Nunes, MD, \\ Department of Otolaryngology, Nucleo de Otorrinolaringologia e \\ Cirurgia de Cabeça e Pescoço de São Paulo, Nhambiquaras, street 159, \\ São Paulo 04090-010, Brazil (e-mail: helo2005@hotmail.com).
}

\begin{abstract}
Introduction The Gastroesophageal Reflux Disease has a prevalence of $\sim 12 \%$ of the urban population in Brazil. Koufman proposed the term to designate Laryngeal Pharyngeal Reflux (LPR) symptoms, signs or tissue damage resulting from aggression of the gastrointestinal contents in the upper aerodigestive tract. Belafsky et al proposed a score that points to inflammatory laryngeal signs through videolaryngoscopic findings, the Reflux Finding Score (RFS). Moreover, in 2002, they published the Reflux Symptom Index (RSI).

Objective The objective of this study is to provide a comparison between the Reflux Finding Score and the Reflux Symptom Index in the practice of Otorhinolaryngology. Methods Our study involved a total of 135 patients who visited the Ear, Nose, and Throat (ENT) clinic Núcleo de Otorrinolaringologia e Cirurgia de Cabeça e Pescoço de São Paulo between April 2014 and May 2015 with suspected LPR. We excluded nine patients and the study group was 126 patients. All patients were ranked by their RSI and RFS scores.

Results The study group consisted of 126 patients ( 88 women and 38 men). Their main complaints were cough $(40.4 \%)$, globus $(21.4 \%)$, dysphonia $(19.8 \%)$, throat

\section{Keywords}

- gastroesophageal reflux disease

- videolaryngoscopy

- laryngopharyngeal reflux clearing $(15.8 \%)$, postnasal drip $(3.17 \%)$, snoring (1.5\%), dysphagia (1.5\%), cacosmia (0.7\%), and regurgitation (1.5\%). The RSI ranges from 13 to 42 with a mean of 20.7 $(S D=6.67)$. The RFS ranged from 3 to 19 with a mean of $9.53(S D=2.64)$.

Conclusion The RSI and RFS can easily be included in ENT routines as objective parameters, with low cost and high practicality. Based on the clinical index, the specialist can evaluate the need for further tests.
\end{abstract}

\section{Introduction}

The Gastroesophageal Reflux Disease has a prevalence of $\sim 12 \%$ of the urban population in Brazil. ${ }^{1}$ It is a disease with a major impact for presenting variable number of symptoms associated with esophageal and / or extra esophageal injury. Supraesophageal symptoms were reported by $58 \%$ of patients

received

July 28, 2015

accepted

October 23, 2015

published online

February 12, 2016
DOI http://dx.doi.org/

10.1055/s-0036-1579557. ISSN $1809-9777$. with classic symptoms such as regurgitation or retrosternal pain and, in these patients, there was a worsening of quality of life score. ${ }^{2}$ In 1996, Koufman proposed the term to designate Laryngeal Pharyngeal Reflux (LPR) symptoms, signs, or tissue damage resulting from aggression of the gastrointestinal contents in the upper aerodigestive tract. ${ }^{3}$ Laryngeal symptoms of reflux represent two or more possible etiologic
Copyright $(2016$ by Thieme Publicações License terms Ltda, Rio de Janeiro, Brazil
(ब) $\Theta \circledast$ 
mechanisms that can act simultaneously: local chemical irritation on the pharyngolaryngeal mucosa or stimulation and vagal reflex from esophageal irritation. ${ }^{4}$

There is wide divergence among specialists on the diagnosis of LPR. Therefore, Belafsky et al recently proposed a score that punctuates laryngeal inflammatory signals through videolaryngoscopic findings, the Reflux Finding Score (RFS), to decrease the subjectivity of diagnosis. ${ }^{5}$ In 2002, Belafsky et al published the Reflux Symptom Index (RSI), ${ }^{6}$ a classification of symptoms of laryngopharyngeal reflux.

The laryngopharyngeal reflux may lead to symptoms such as globus or lump feeling in the throat, dry cough, throat clearing, posterior discharge, dysphonia, difficulty swallowing solids, liquids or pills, difficulty breathing or episodes of asphyxia, heartburn, chest pain, indigestion, or regurgitation.

To minimize the underdiagnosis, this study aims to compare the Reflux Finding Score (RFS) with the Reflux Symptom Index (RSI) in the practice of ENT.

\section{Material and Methods}

We surveyed 135 patients, although we excluded nine patients with suspected laryngopharyngeal reflux because they had not reached the minimum of 13 RSI score. Therefore, the study group included 126 patients ( 88 women and 38 men) between April 2014 and May 2015 who visited the ENT Clinic Center at the Núcleo de Otorrinolaringologia e Cirurgia de Cabeça e Pescoço de São Paulo with suspected laryngopharyngeal reflux. We classified all patients classified according to gender, age, and ranked them by their main results. We also requested nasofibrolaryngoscopy for all these patients to compare the results.

A single physician performed nasofibrolaryngoscopy in all subjects.

We used the symptom questionnaire and the classification proposed by Belafsky et al ( - Table $1,-$ Table 2 ).

Patients with allergy symptoms such as rhinitis and pharyngitis or tumor lesions were excluded. The age distribution
Table 1 Reflux Finding Score

\begin{tabular}{|l|l|}
\hline Subglottic edema & $0=$ absent \\
\hline & $2=$ present \\
\hline Ventricular & $2=$ partial \\
\hline & $4=$ complete \\
\hline Erythema/hyperemia & $2=$ arytenoids only \\
\hline & $4=$ diffuse \\
\hline Vocal fold edema & $1=$ mild \\
\hline & $2=$ moderate \\
\hline & $3=$ severe \\
\hline & $4=$ polypoid \\
\hline Diffuse laryngeal edema & $1=$ mild \\
\hline & $2=$ moderate \\
\hline & $3=$ severe \\
\hline & $4=$ obstructing \\
\hline Posterior commissure hypertrophy & $1=$ mild \\
\hline & $2=$ moderate \\
\hline & $3=$ severe \\
\hline & $4=$ obstructing \\
\hline Granuloma/granulation tissue & $0=$ absent \\
\hline & $2=$ present \\
\hline Thick endolaryngeal mucus & $0=$ absent \\
\hline & $2=$ present \\
\hline
\end{tabular}

Abbreviation: RFS, Reflux Finding Score. RSF $>7$ = Laryngo Pharyngeal Reflux (LPR).

was 19 to 88 years old, with a mean age of 52.44 years $(\mathrm{SD}=13.89)$. For the RSI, the patients themselves assign points to nine symptoms that are often observed in patients with LPR. A score above 13 is considered positive for LPR. We did not request a nasofibrolaryngoscopy for the nine patients who did not achieve a minimum score on the RFS.

Table 2 Reflux Symptom Index

\begin{tabular}{|c|c|c|c|c|c|c|}
\hline Within the last Month, how did the following problems affect you? & \multicolumn{6}{|c|}{$\begin{array}{l}0=\text { no problem } \\
5=\text { severe problem }\end{array}$} \\
\hline 1. Hoarseness or a problem with your voice & 0 & 1 & 2 & 3 & 4 & 5 \\
\hline 2. Clearing your throat & 0 & 1 & 2 & 3 & 4 & 5 \\
\hline 3. Excess throat mucus or postnasal drip & 0 & 1 & 2 & 3 & 4 & 5 \\
\hline 4. Difficulty swallowing food, liquids, or pills & 0 & 1 & 2 & 3 & 4 & 5 \\
\hline 5. Coughing after you ate or after lying down & 0 & 1 & 2 & 3 & 4 & 5 \\
\hline 6. Breathing difficulties or choking episodes & 0 & 1 & 2 & 3 & 4 & 5 \\
\hline 7. Troublesome or annoying cough & 0 & 1 & 2 & 3 & 4 & 5 \\
\hline 8. Sensation of something sticking in your throat or a lump in your throat & 0 & 1 & 2 & 3 & 4 & 5 \\
\hline 9. Heartburn, chest pain, indigestion, or stomach acid coming up & 0 & 1 & 2 & 3 & 4 & 5 \\
\hline $\mathrm{RSI}>13=$ Abnormal & \multicolumn{6}{|c|}{ Total } \\
\hline
\end{tabular}

Abbreviation: RSI, reflux symptom index.

Source: Belafsky et al, ${ }^{6}$ with permission from Elsevier Science 


\section{Results}

We excluded 9 of the 135 patients, because they did not meet the criteria of RSI or RFS despite the clinical suspicion. The study group included 126 patients. The main complaints were cough in 51 patients (40.4\%), globus in 27 patients (21.4\%), dysphonia was present in 25 (19.8\%), throat clearing in 20 (15.8\%), postnasal drip in 4 patients $(3.17 \%)$, snoring in 2 (1.5\%), dysphagia in $2(1.5 \%)$, cacosmia in $1(0.7 \%)$, and regurgitation in 2 (1.5\%) (-Table $\mathbf{1}$ ).

The RSI ranges from 13 to 42 with a mean of 20.7 (SD $=6.67)$. The RFS ranged from 3 to 19 with a mean of 9.53 $(\mathrm{SD}=2.64)$.

We considered the RSI as positive when reflux was higher than or equal to 13 and / or RFS equal or higher than 7. Only seven patients out of 126 had a positive score on RSI with a negative score on RFS (-Fig. 1 ).

As isolated data, we observed one case of vocal fold hematoma, one case of granuloma, and two patients with varicosity.

\section{Discussion}

The word reflux [derived from the Latin re ("back") and fluere ("flow")] literally means back flow. The gastro esophageal reflux (GER) refers to the reflux of stomach contents into the esophagus, which may be physiological, and could occur up to 50 times a day, especially after meals. Gastro esophageal reflux disease (GERD) is a clinical term that refers to GER that is excessive and causes tissue damage or clinical symptoms. $^{7}$

LPR is a term used since 1996 by Koufman et al to designate symptoms, signs, or tissue damage resulting from the return of gastroduodenal contents into the upper aerodigestive tract. $^{3}$ In our study, we obtained higher prevalence of LPR in women (69\%). Their common symptoms are sore throat, pharyngeal globus, throat clearing, dysphonia, dry cough, and laryngospasm crises. ${ }^{8}$ We can refer to LPR as extra esophageal reflux. ${ }^{7}$ In our study with 126 patients, there was a predominance of dry cough as a symptom in $40.4 \%$; whereas the main complaint in the literature we analyzed was globus. ${ }^{9}$

Patients with LPR appear to have different pathogenic mechanisms as different symptoms and different response

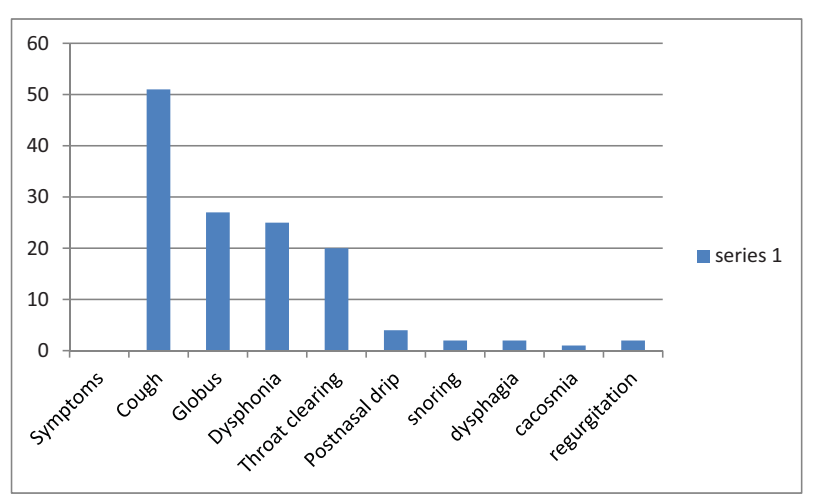

Fig. 1 Symptons distribuction. to treatment, compared with patients with GERD. The main difference between the two entities is that most patients with LPR do not have heartburn and esophagitis. Patients with LPR mainly have reflux during the day, while those with GERD have reflux during the night. Also, there is prolonged acid exposure in GERD, but not in LPR. ${ }^{7}$

Prolonged esophageal monitoring tests help to diagnose the disease; however, despite being highly specific, such tests have low sensitivity, especially in cases of laryngopharyngeal reflux. The esophageal $\mathrm{pH}$ monitoring is possible using one or two sensors. The second type is indispensable when there is suspicion of laryngopharyngeal reflux. The difficulties related to the acceptance of the technical examination and the limitations (it only detects episodes of liquid and acid reflux) led to esophageal $\mathrm{pH}$-impedance development, a technique that allows the evaluation of reflux liquid or gaseous content, whether it is acid or not. However, both tests have a difficult health care access, especially in developing countries, in addition to poor adherence among patients, due to the inconvenience suffered during the procedure. ${ }^{8}$

The diagnostic evaluation also includes laryngoscopy video examination, which allows physicians to check for suggestive signs, albeit not specific to reflux, such as edema and diffuse laryngeal hyperemia, edema of the vocal folds, edema of vestibular folds, edema of the subglottic mucosa, interarytenoid region hypertrophy, thick endolarynx mucus, and granuloma or granulation tissue. Since these signs of inflammation are common to other diseases affecting the larynx and pharynx, diagnosing the disease remains quite difficult. ${ }^{8}$ The main nasofibrolaryngoscopy finding suggestive of LPR in the study was arytenoids hyperemia and posterior commissure hypertrophy. One patient had granuloma and we observed no cases of subglottic stenosis. This finding is important because it shows that the subglottic stenosis is rare or difficult to visualize in ENT practice.

To minimize the subjectivity of these evaluations, a group of researchers proposed a scoring system, the RFS, based on the endolaryngeal inflammatory findings supposedly suggestive of reflux. This index has been validated in English in 2001 by Belafsky et al and has been widely used in the literature as a diagnosis parameter of LPR. The rating score allocates intensity degrees of inflammatory signs and the presence or absence of lesions suggestive of the disease. The RFS has demonstrated high reproducibility and reliability, and a patient with scores above 7 points has $94 \%$ probability of presenting LPR. This instrument has also been used to monitor the diseasés evolution and response to the treatment. ${ }^{12}$ In this study, we evaluated the nasofibrolaryngoscopy according to video and revised it in relation to the report.

Several published reports observe the RFL association with other laryngeal diseases. Kuhn et $\mathrm{al}^{11}$ found a higher incidence of LPR in patients with vocal fold nodules as compared with control individuals. Morrison et $\mathrm{al}^{10}$ found an association between reflux and tension dysphonia. In a comprehensive study of LPR, Koufman ${ }^{11}$ observed a significant association between LPR and a variety of laryngeal diseases. In this study, only one patient had vocal fold hematoma which could relate to other laryngeal pathologies. 
In most patients, the RSI and RFS were positive. This shows that the RSI is an important clinical parameter to be considered in diagnosis. Physicians can evaluate it independently and it indicates whether or not to proceed with other tests, given the significant correlation between such symptomatic and endoscopic parameters. $5,6,12$

\section{Conclusion}

The RSI and RFS can easily be included in ENT routine as objective parameters, with low cost and good practicality. According to the clinical index it can evaluate the need for further tests.

\section{References}

1 Moraes-Filho JP, Chinzon D, Eisig JN, Hashimoto CL, Zaterka S. Prevalence of heartburn and gastroesophageal reflux disease in the urban Brazilian population. Arq Gastroenterol 2005;42(2): 122-127

2 Mearin F, Ponce J, Ponce M, Balboa A, Gónzalez MA, Zapardiel J. Frequency and clinical implications of supraesophageal and dyspeptic symptoms in gastroesophageal reflux disease. Eur J Gastroenterol Hepatol 2012;24(6):665-674

3 Koufman J, Sataloff RT, Toohill R. Laryngopharyngeal reflux: consensus conference report. J Voice 1996;10(3):215-216
4 Eckley CA, Costa HO. Comparative study of salivary pH and volume in adults with chronic laryngopharyngitis by gastroesophageal reflux disease before and after treatment. Braz J Otorhinolaryngol 2006;72(1):55-60

5 Belafsky PC, Postma GN, Koufman JA. The validity and reliability of the reflux finding score (RFS). Laryngoscope 2001;111(8):1313-1317

6 Belafsky PC, Postma GN, Koufman JA. Validity and reliability of the reflux symptom index (RSI). J Voice 2002;16(2):274-277

7 Koufman JA, Aviv JE, Casiano RR, Shaw GY. Laryngopharyngeal reflux: position statement of the committee on speech, voice, and swallowing disorders of the American Academy of Otolaryngology-Head and Neck Surgery. Otolaryngol Head Neck Surg 2002; 127(1):32-35

8 Almeida AGP, Saliture TBS, Silva ASS, Eckley CA. Translation and cultural adaptation of the Reflux Finding Score into Brazilian Portuguese. Braz J Otorhinolaryngol 2013;79(1):47-53

9 Park KH, Choi SM, Kwon SU, Yoon SW, Kim SU. Diagnosis of laryngopharyngeal reflux among globus patients. Otolaryngol Head Neck Surg 2006;134(1):81-85

10 Morrison MD, Nichol H, Rammage LA. Diagnostic criteria in functional dysphonia. Laryngoscope 1986;96(1):1-8

11 Koufman JÁ. The otolaryngologic manifestations of gastroesophageal reflux disease (GERD): a clinical investigation of 225 patients using ambulatory 24-hour $\mathrm{pH}$ monitoring and an experimental investigation of the role of acid and pepsin in the development of laryngeal injury. Laryngoscope 1991;101(4 Pt 2, Suppl 53)1-78

12 Mesallam TA, Stemple JC, Sobeih TM, Elluru RG. Reflux symptom index versus reflux finding score. Ann Otol Rhinol Laryngol 2007; 116(6):436-440 